\title{
High-glucose microenvironment promotes perineural invasion of pancreatic cancer via activation of hypoxia inducible factor $1 \alpha$
}

\author{
LUN ZHANG $^{1}$, WUNAI ZHANG ${ }^{1}$, XIN ZHANG $^{2}$, YIHE MIN $^{3}$, YANG ZHAO $^{2}$, \\ BAOFENG WANG ${ }^{2}$, WEI LI ${ }^{1}$, SHUAI MAO ${ }^{4}$ and WEILI MIN ${ }^{2}$ \\ ${ }^{1}$ Department of Hepatobiliary Surgery, First Affiliated Hospital of Xi'an Jiaotong University, Xi'an, Shaanxi 710061; \\ ${ }^{2}$ Department of Oncology, Second Affiliated Hospital of Xi'an Jiaotong University, Xi'an, Shaanxi 710004; \\ ${ }^{3}$ Chongqing Three Gorges Medical College, Chongqing 404100; ${ }^{4}$ Department of Medicinal Chemistry, \\ School of Pharmacy, Xi'an Jiaotong University, Xi'an, Shaanxi 710061, P.R. China
}

Received April 4, 2021; Accepted June 29, 2021

DOI: $10.3892 /$ or.2022.8275

\begin{abstract}
Pancreatic cancer (PC) is one of the most lethal diseases, with a 5-year survival rate of $<9 \%$. Perineural invasion (PNI) is a common pathological hallmark of PC and is correlated with a poor prognosis in this disease. Hyperglycemia has been shown to promote the invasion and migration of PC cells; however, the effect of hyperglycemia on the PNI of PC and its underlying mechanism remains unclear. In the present study, Western blotting was utilized to detect the expression of hypoxia inducible factor $1 \alpha(\mathrm{HIF} 1 \alpha)$ and nerve growth factor (NGF). Transwell and wound-healing assays were performed to detect the influence of hyperglycemia on the invasion and migration ability of PC cells. An in vitro $\mathrm{PC}$-dorsal root ganglion (DRG) co-culture system and an in vivo PNI sciatic nerve-infiltrating tumor model were used to evaluate the severity of PNI in hyperglycemic conditions. In the results, hyperglycemia promoted the invasion/migration ability and elevated the expression of NGF in PC by upregulating HIF1 $\alpha$. Moreover, in vitro short-term hyperglycemia caused little damage on the DRG axons and accelerated both the PNI of the PC and the outgrowth of the DRGs by increasing the expression of NGF via activation of HIF1 $\alpha$. Indeed, in vivo long-term hyperglycemia promoted the infiltration and growth of PC, and then disrupted the function of the sciatic nerve in a HIF1 $\alpha$-dependent manner. In conclusion, a high-glucose microenvironment promotes PNI of PC via activation of HIF1 $\alpha$.
\end{abstract}

Correspondence to: Dr Weili Min, Department of Oncology, Second Affiliated Hospital of Xi'an Jiaotong University, 157 Xiwu Road, Xincheng, Xi'an, Shaanxi 710004, P.R. China E-mail: mw1791218@126.com

Abbreviations: PC, pancreatic cancer; PNI, perineural invasion; DRGs, dorsal root ganglions; NGF, nerve growth factor; HIF1 $\alpha$, hypoxia inducible factor $1 \alpha$; PDAC, pancreatic ductal adenocarcinoma; TME, tumor microenvironment

Key words: PC, PNI, hyperglycemia, HIF1 $\alpha$

\section{Introduction}

Pancreatic cancer (PC), with a 5-year survival rate of $<9 \%$, is one of the most lethal diseases, and it is the fourth leading cause of cancer-related death in the United States (1). Most patients with PC are diagnosed in an advanced stage and miss their best opportunity for surgery (2). The lack of any effective adjuvant chemotherapies also hinders their survival. Our current limited understanding of the risk factors and the tumorigenesis mechanism is an important reason for the poor prognosis of PC (3). Hence, additional studies, including research exploring the etiology of $\mathrm{PC}$ and searching for possible pro-tumor factors, should be performed to improve the prognosis of PC.

Pancreatic ductal adenocarcinoma (PDAC) is the most common pathological type of $\mathrm{PC}$, and its high proliferation rate, abundant desmoplastic reactions, and propensity for perineural invasion (PNI) are its main pathological features (4). Previous studies have shown that the incidence of PNI in PC is nearly $100 \%$ and that it is closely related to the poor prognosis of PC $(4,5)$. PNI is defined as the cancer cells surrounding the nerves and/or invading into the spaces of the epineurium, perineurium or endoneurium (6-8). Both in vitro and in vivo studies found that PC cells, and even precancerous pancreatic cells, can approach and invade the nerves, and then migrate/disseminate along the nerves to distant organs or tissues; in addition, PC cells also hide in nerves, which can cause in situ recurrences of PC $(9,10)$. The interaction of the tumor cells and nerves promotes the formation of PNI. However, the underlying mechanism of PNI and its role in PC development remain unclear.

Increasing amounts of evidence have indicated that hyperglycemia is a risk factor for $\mathrm{PC}$, and patients with long-standing type 2 diabetes mellitus have a two-fold increased risk of PC (11-13). In addition, apart from its pro-initiation effect, hyperglycemia also facilitates the progression of PC via modulation of its proliferation and invasion/migration, and by inducing chemoresistance among PC (14). Notably, studies found that increased PNI of PC was correlated with hyperglycemia both in animals and in patients $(15,16)$. The possible reason for this phenomenon may be that hyperglycemia 
supports the malignant behavior of PC and modulates the expression of nerve growth factor (NGF), a prominent neurotrophic factor involved in PNI, and then promotes the outgrowth of nerve axons $(17,18)$.

The present study evaluates the effect of hyperglycemia on the migration ability and PNI of PC, trying to explain the underlying mechanism linking hyperglycemia and PNI in PC.

\section{Materials and methods}

Cell lines and cultures. The PC BxPc-3 and Panc-1 cell lines were obtained from the Type Culture Collection of the Chinese Academy of Sciences and cultured in DMEM (Gibco; Thermo Fisher Scientific, Inc.) with $10 \%$ fetal bovine serum (FBS; HyClone; Cytiva) and 1\% penicillin-streptomycin (Gibco; Thermo Fisher Scientific, Inc.) in a standard incubator with a $5 \% \mathrm{CO}_{2}$ atmosphere at $37^{\circ} \mathrm{C}$. To induce normal or high-glucose environments, $0,5.5$ or $25 \mathrm{mM}$ glucose was added to DMEM (mannitol was used to balance the osmotic pressure). After grouping and intervention, relevant assays were performed on the $0-\mathrm{mM}$ glucose group, the euglycemia group $(5.5 \mathrm{mM})$ and the hyperglycemia group $(25 \mathrm{mM})$, and then the total protein was extracted by RIPA buffer (Beyotime Institue of Biotechnology) from the cells as required.

Animal experiments. All nude mice and newborn rats were reared in a specific pathogen-free chamber, with the temperature controlled at $24^{\circ} \mathrm{C}$ and a $12 / 12 \mathrm{~h} \mathrm{light/dark} \mathrm{cycle,} \mathrm{at} \mathrm{the}$ Animal Center of Xi'an Jiaotong University (Xi'an, China). The relative humidity in the chamber was $50-80 \%$. An ultraviolet lamp installed in the chamber was used to keep sterile conditions. Food, water and bedding used by the nude mice was provided ad libitum and newborn rats were all sterilized. A total of 18 male nude mice (6 mice per group) and 6 male newborn rats ( 1 day old, weighing $\sim 1.5 \mathrm{~g}$ ) were used to perform this study. The average weight of the nude mice at the start of the experiment was $\sim 20 \mathrm{~g}$ (age, 6 weeks). The experimental protocols were approved by the Ethical Committee of the First Affiliated Hospital of Xi'an Jiaotong University. This study was conducted in accordance with the Declaration of Helsinki, and all protocols were approved by the Ethical Committee of the First Affiliated Hospital of Xi'an Jiaotong University.

In vitro PNI co-culture model. The PNI co-culture model can mimic the peripheral nerve microenvironment of PC tumor tissues (7). Briefly, the construction of this model is separated into three parts: PC cell inoculation, dorsal root ganglion (DRG) extraction and DRG implantation.

$P C$ cell inoculation. The PC cells were pretreated with the aforementioned different glucose levels according to the experimental requirements. Next, $40 \mu 1$ PC cells $\left(1 \times 10^{5}\right.$ cells/well $)$ were inoculated into 24-well culture plates to form a round island of cells (no extra medium was added to maintain the morphological integrity of the cell islands). The 24-well culture plates were incubated in a standard incubator with a $5 \% \mathrm{CO}_{2}$ atmosphere at $37^{\circ} \mathrm{C}$ for $\sim 8 \mathrm{~h}$.

$D R G$ extraction. Newborn rats (1-3 days after birth; purchased from the Experimental Animal Center of Xi'an Jiaotong
University) were euthanized with $\mathrm{CO}_{2}$, with a chamber volume displacement rate of $10-30 \%$ per minute (experiments performed in 2019). The rats were then sterilized with $75 \%$ ethanol (cervical dislocation was not performed to guarantee the spinal nerve structure). Next, dissection was performed and the entire spine, which contained parts of both sides of the ribs, was obtained and immediately placed into $4^{\circ} \mathrm{C}$ PBS. After placing the spine in cold PBS on ice, the dorsal nerve roots between the ribs and the spine were exposed to access the DRGs. Finally, the residual nerve roots and fibrous tissue were carefully trimmed from around the DRGs.

DRG implantation. After $8 \mathrm{~h}$ of incubation, the curved boundary of the round cell islands in the 24-well culture plates were clearly delimited. Next, one DRG was implanted behind the cell island, keeping the distance between the edges of the two structures $\sim 2 \mathrm{~mm}$ apart. A drop of growth factor-depleted liquid Matrigel (BD Biosciences) was applied to fix and nourish the DRGs. Subsequently, the 24-well culture plates were placed into a standard incubator with a $5 \% \mathrm{CO}_{2}$ atmosphere at $37^{\circ} \mathrm{C}$ for $30-40 \mathrm{~min}$ to induce Matrigel solidification. After solidification, culture media was added carefully to each well, which was replenished every 2 days.

To quantitate the severity of the PNI in this co-culture model, the initial distance $(\sim 2 \mathrm{~mm})$ between the edge of the cell island and the DRG was defined as parameter $\gamma$, the relative migration distance of the PC cells toward the DRG was defined as parameter $\alpha$ and the relative outgrowth of the DRGs axons toward the PC cells was defined as parameter $\beta$. The PC cell invasion index $=\alpha / \gamma$, and the DRG outgrowth index $=\beta / \gamma$ (Fig. 2A). These parameters were measured by the image processing/analysis software ImageJ (version 1.52a; National Institutes of Health).

In vivo PNI sciatic nerve infiltrating tumor model. As described previously $(19,20)$, the sciatic nerve infiltrating tumor model was adopted to research the influence of hyperglycemia on PNI of PC in vivo. Briefly, the construction of this model is separated into three parts, the induction of hyperglycemia in mice, the transplanting of PC cells into the mouse sciatic nerve and the relative intervention strategy.

Induction of hyperglycemia in mice. Female 4-week-old $\mathrm{BALB} / \mathrm{c}$ nude mice were purchased from and reared in the Experimental Animal Center of Xi'an Jiaotong University. The mice were separated into three groups (6 mice/group); two groups (control group and 2-ME group) received an intraperitoneal injection of streptozotocin (STZ; MedChem Express; dissolved in sodium citrate buffer, $150 \mathrm{mg} / \mathrm{kg}$ ) to induce hyperglycemia, while the third group received an intraperitoneal injection of sodium citrate buffer alone as the euglycemic control. After 7 days, the blood glucose levels of each mouse were measured to confirm establishment of the model.

Transplantation of PC cells into the mouse sciatic nerve. First, the mice were anesthetized with $1 \%$ pentobarbital sodium $(50 \mathrm{mg} / \mathrm{kg}$, intraperitoneal injection) and the sciatic nerve of the left lower extremity was exposed. Next, $5 \mu 1$ Panc-1 cell suspension $\left(1 \times 10^{5}\right.$ cells/well) was slowly (over $\sim 2 \mathrm{~min}$ ) injected into the perineurium of the sciatic nerve using a $10-\mu 1$ 
micro-syringe. Finally, the wound was sutured and the general status of the mice was observed for 2 weeks.

Relative intervention strategy. Three strategies were performed in this study to form the following groups: The euglycemia group (saline, $0.1 \mathrm{ml} / \mathrm{mice}$, intraperitoneal injection, daily), the hyperglycemia group (saline, $0.1 \mathrm{ml} / \mathrm{mice}$, intraperitoneal injection, daily) and the hyperglycemia plus 2-mercaptoethanol (2-ME) group (MedChem Express; inhibitor of HIF1 $\alpha$; $50 \mathrm{mg} / \mathrm{kg}$, intraperitoneal injection, daily for 4 weeks).

Considering that the sciatic nerve innervates the hind limb paw muscles, a sciatic nerve score [the nerve function was graded from 4 (normal paw function) to 1 (total paw paralysis) based on the hind limb paw response to manual extension of the body] and the distance of the paw span (the length between the first and fifth toes of the hind limbs) were used as the evaluation indices of sciatic nerve function. Finally, the nude mice were euthanized with $\mathrm{CO}_{2}$, with a chamber volume displacement rate of $10-30 \%$ per minute. Consequently, the generated tumors were extracted to calculate their volume.

Small interfering (si)RNA transfections. HIF1 $\alpha$-specific siRNA (si-HIF1 $\alpha$; sense, 5'-CCACCACUGAUGAAUUAA ATT-3'; anti-sense, 5'-UUUAAUUCAUCAGUGGUGGTT-3') and a negative control scrambled siRNA (si-NC; sense, 5'-UUC UCCGAACGUGUCACGUTT-3'; anti-sense, 5'-ACGUGA CACGUUCGGAGAATT-3') were purchased from Shanghai GenePharma Co., Ltd. Glucose pretreated cells or the non-treated cells seeded in 6-well plates were transfected with $100 \mathrm{nM}$ siRNA (50 pmol/well) using the Lipofectamine ${ }^{\circledR}$ RNAi MAX Reagent (Invitrogen; Thermo Fisher Scientific, Inc.) for $48 \mathrm{~h}$ at $25^{\circ} \mathrm{C}$ according to the manufacturer's instructions. The cells were used in subsequent experiments $24 \mathrm{~h}$ after the transfection.

Cell invasion assay. Transwell Matrigel invasion assays were adopted to measure the invasive ability of the PC cells. First, 8 -mm pore Millicell inserts were coated with $25 \mu$ l Matrigel at $37^{\circ} \mathrm{C}$ for $8 \mathrm{~h}$. PC cells (BxPc-3 and Panc-1) were pretreated appropriately according to the design of the study, and cell suspensions $\left(5 \times 10^{4} /\right.$ well) were added to the upper chambers in DMEM containing 1\% FBS. Next, $500 \mu 1$ DMEM containing $20 \%$ FBS was placed in the lower chambers. After being incubated for $48 \mathrm{~h}$, the non-invading cells were removed by cotton swab and the invading cells were stained with crystal violet at room temperature for $15 \mathrm{~min}$. The invasion ability was determined by counting the stained cells on the bottom surface of the insert under a light microscope.

Cell migration assay. Wound-healing assays were adopted to measure the migration ability of the PC cells. PC cells (BxPc-3 and Panc-1) were pretreated appropriately according to the design of the study. The PC cells were serum-starved during the assay. A sterile pipette tip was used to produce a wound line across the plate after the cells had been grown to 90-100\% confluence. The cells were allowed to migrate for 48 $\mathrm{h}$. Images were captured at 0 and $48 \mathrm{~h}$ post-wounding using a light microscope and the relative migration area was measured by image processing/analysis software ImageJ (version 1.52a; National Institutes of Health).
Western blot assays. PC cells (BxPc-3 and Panc-1) were pretreated appropriately according to the design of the experiment and total protein was extracted using RIPA lysis buffer (Beyotime Institute of Biotechnology). Next, western blotting assays were performed as previously described (21). Primary antibodies against HIF1 $\alpha$ (1:1,000; catalog no. ab51608; Abcam), NGF (1:1,000; catalog no. ab52918; Abcam) and $\beta$-actin (1:5,000; catalog no. 20536-1-AP; ProteinTech Group, Inc.) were incubated at $4^{\circ} \mathrm{C}$ for $12 \mathrm{~h}$. Next, the goat anti-rabbit HRP-conjugated secondary antibody (catalog no. A0208; Beyotime Insititute of Biotechnology) was diluted at 1:10,000 and incubated for $1 \mathrm{~h}$ at room temperature. Subsequently, ECL luminescence reagent (Beyotime Institute of Biotechnology) was applied for $\sim 5 \mathrm{~min}$. Images of the immunopositive bands were captured with a ChemiDoc XRS imaging system (Bio-Rad Laboratories, Inc.) and Image Lab (version 3.0 Beta 3; Bio-Rad Laboratories, Inc.) was used for densitometry analysis. Grayscale analysis was performed using ImageJ (version 1.52a; National Institutes of Health).

Bioinformatics analysis. Two online bioinformatics analysis websites, GEPIA (http:/gepia.cancer-pku.cn/) and Kaplan-Meier Plotter (http://www.kmplot.com) were used to perform the bioinformatics analysis in this passage. Firstly, the Kaplan-Meier Plotter website was adopted to analysis the relapse-free survival and overall survival rates with regard to HIF1 $\alpha$ and pancreatic cancer. A PDAC dataset $(n=177)$ in the pan-cancer database (mRNA RNA-Seq sub-database) was divided based on the median value. Next, on the GEPIA website, the PAAD dataset was adopted to analyze the expression level of HIF1 $\alpha$ in pancreatic cancer (179 cases) and normal pancreas (171 cases). ILog2FCl and $\mathrm{P}<0.01$ were used as the cut-offs. The correlation between HIF1 $\alpha$ and NGF/BDNF in pancreatic cancer was performed via automatic analysis on the GEPIA website.

Statistical analysis. The data are presented as the mean \pm SD. Using the GraphPad Prism software package (version 6.0; Graphpad Software, Inc.), the differences in the in vivo data were assessed with Student's t-test (unpaired) when there were 2 groups. Dunnett's post hoc test in conjunction with one-way ANOVA was performed to compare the differences between the control group and other groups when there were 3 groups. Pearson's correlation test was applied for bioinformatics analysis. All tests were two-sided, and a $\mathrm{P}<0.05$ was considered to indicate a statistically significant difference.

\section{Results}

Hyperglycemia promotes the invasion and migration of $P C$ cells and has little effect on the outgrowth of DRGs. The necessary condition for PNI is a high invasion/migration ability of PC cells. Hence, before the research on the PNI of PC, the influence of hyperglycemia on the invasion/migration ability of the PC cells was first evaluated. Transwell assays showed that $5.5 \mathrm{mM}$ glucose (euglycemia) had little effect on the invasion ability of PC cells compared to the normal media group; however, $25 \mathrm{mM}$ glucose (hyperglycemia) promoted PC cell invasion (Fig. 1A and B). Wound-healing assays also revealed that both euglycemia (5.5 mM glucose) and hyperglycemia (25 mM glucose) accelerated the migration ability of the PC 
A

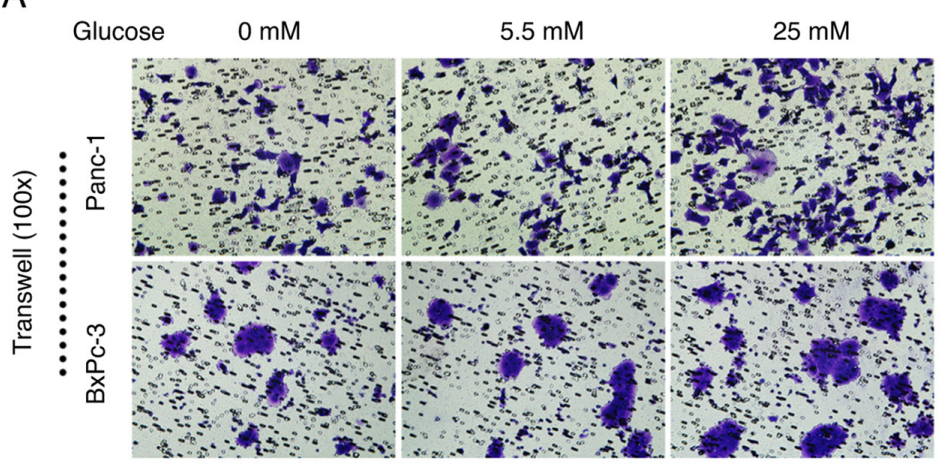

C

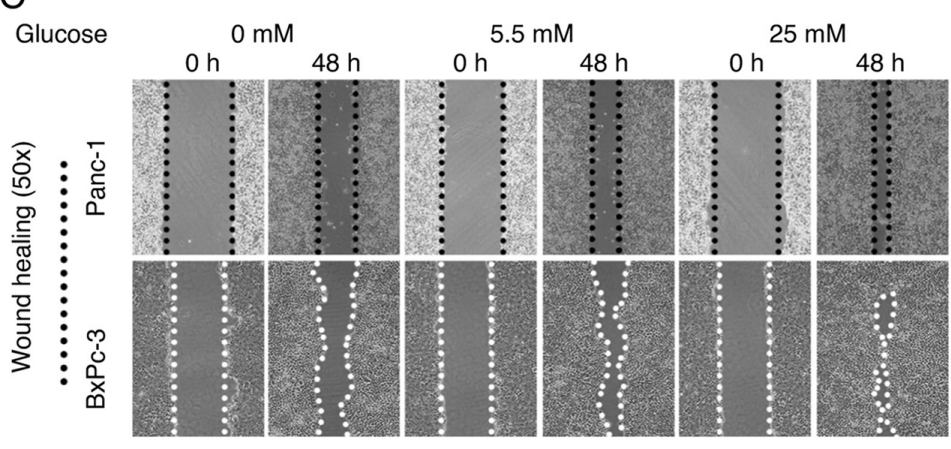

B

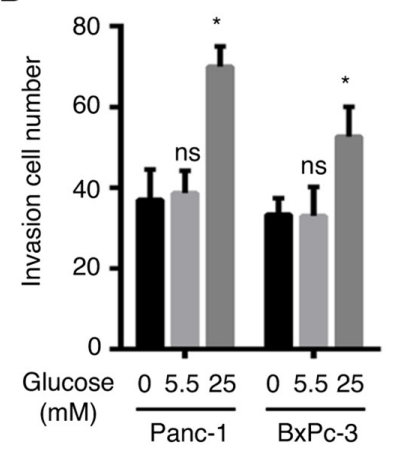

D

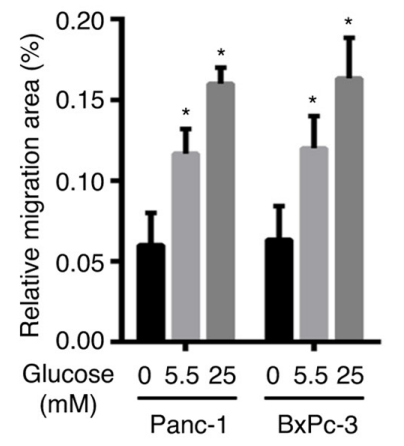

$25 \mathrm{mM}$

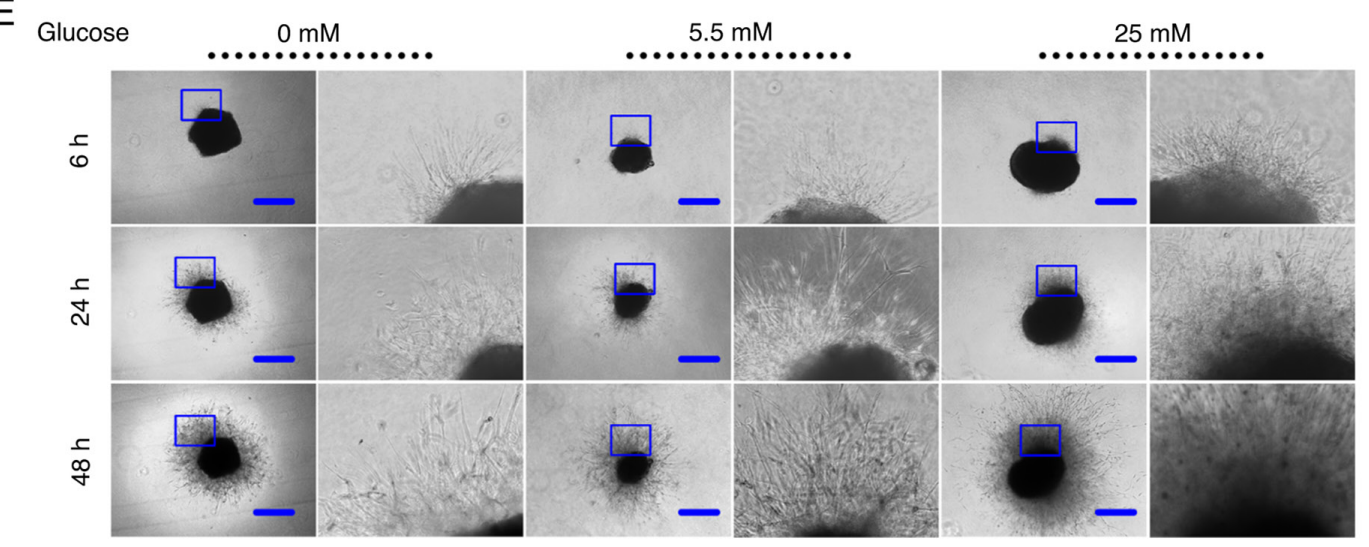

Figure 1. Hyperglycemia promotes the invasion and migration of pancreatic cancer cells and affects the outgrowth of DRGs. (A and B) Cell invasive ability of the negative control ( $0 \mathrm{mM}$ glucose), euglycemia ( $5.5 \mathrm{mM}$ glucose) and hyperglycemia ( $25 \mathrm{mM}$ glucose) groups in BxPC-3 and Panc-1 cells assessed using (A) a Transwell assay (crystal violet staining; x100 magnification), with (B) the associated quantification. (C and D) Cell migration ability of the negative control (0 mM glucose), euglycemia ( $5.5 \mathrm{mM}$ glucose) and hyperglycemia ( $25 \mathrm{mM}$ glucose) groups in BxPC-3 and Panc-1 cells assessed using (C) a wound-healing assay (x50 magnification), with (D) the associated quantification. (E) Dorsal root ganglion axon outgrowth in the conditioned media containing $0,5.5$ and $25 \mathrm{mM}$ glucose following intervention for 6,24 and $48 \mathrm{~h}$. " $\mathrm{P}<0.05$ vs. negative control. Scale bar, $500 \mu \mathrm{m}$. ns, not significant.

cells compared with the normal media group (Fig. 1C and D). These phenomena revealed that hyperglycemia promoted the invasion/migration of PC cells, which indicated that hyperglycemia may participate in the PNI of PC.

Next, a PC cell-DRG direct co-culture system was used to explore the association between hyperglycemia and PNI. The main focus was placed on the influence of hyperglycemia on $\mathrm{PC}$, so different concentrations of glucose $(0,5.5$ and $25 \mathrm{mM})$ were first used to culture the DRGs alone and the outgrowth of the DRG axons was observed. The results showed that short-term intervention ( $<3$ days) exposure to glucose had no marked influence on the outgrowth of the DRGs (Fig. 1E); however, as the time was extended ( $>3$ days; data not shown), hyperglycemia began to suppress the growth of the axons, which may be due to its destruction of the Schwann cells (16).
All of these findings suggested that hyperglycemia promoted the invasion and migration of PC cells and had little effect on the outgrowth of DRGs; thus, the PC cell-DRG direct co-culture system can be adopted for in vitro PNI research.

Hyperglycemia increases NGF expression and accelerates the PNI of PC. As shown in Fig. 2A, to evaluate the severity of PNI in the PC cell-DRG co-culture model, the initial distance ( $\sim 2 \mathrm{~mm}$ ) between the edge of the cell island and the DRG was defined as parameter $\gamma$, the relative migration distance of the PC cells toward the DRG as parameter $\alpha(\mathrm{PC}$ invasion index $=\alpha / \gamma)$ and the relative outgrowth of the DRG axons toward the PC cells as parameter $\beta$ (DRG outgrowth index $=\beta / \gamma$ ). Considering that NGF is an essential member of the neurotrophic family that sustains the PNI of PC, the influence of hyperglycemia on the 
A

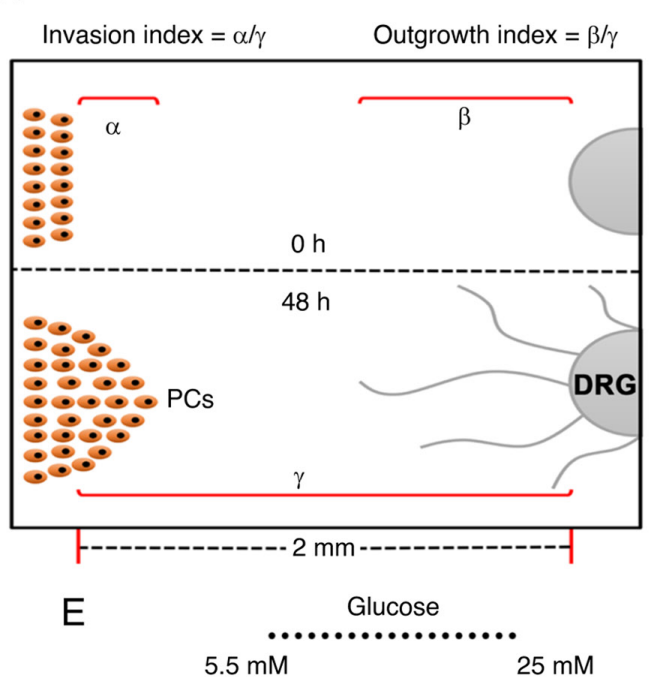

B
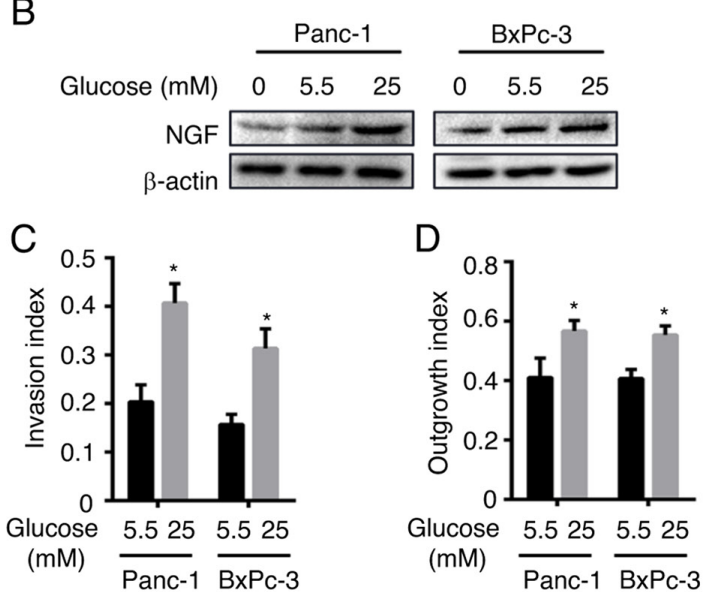

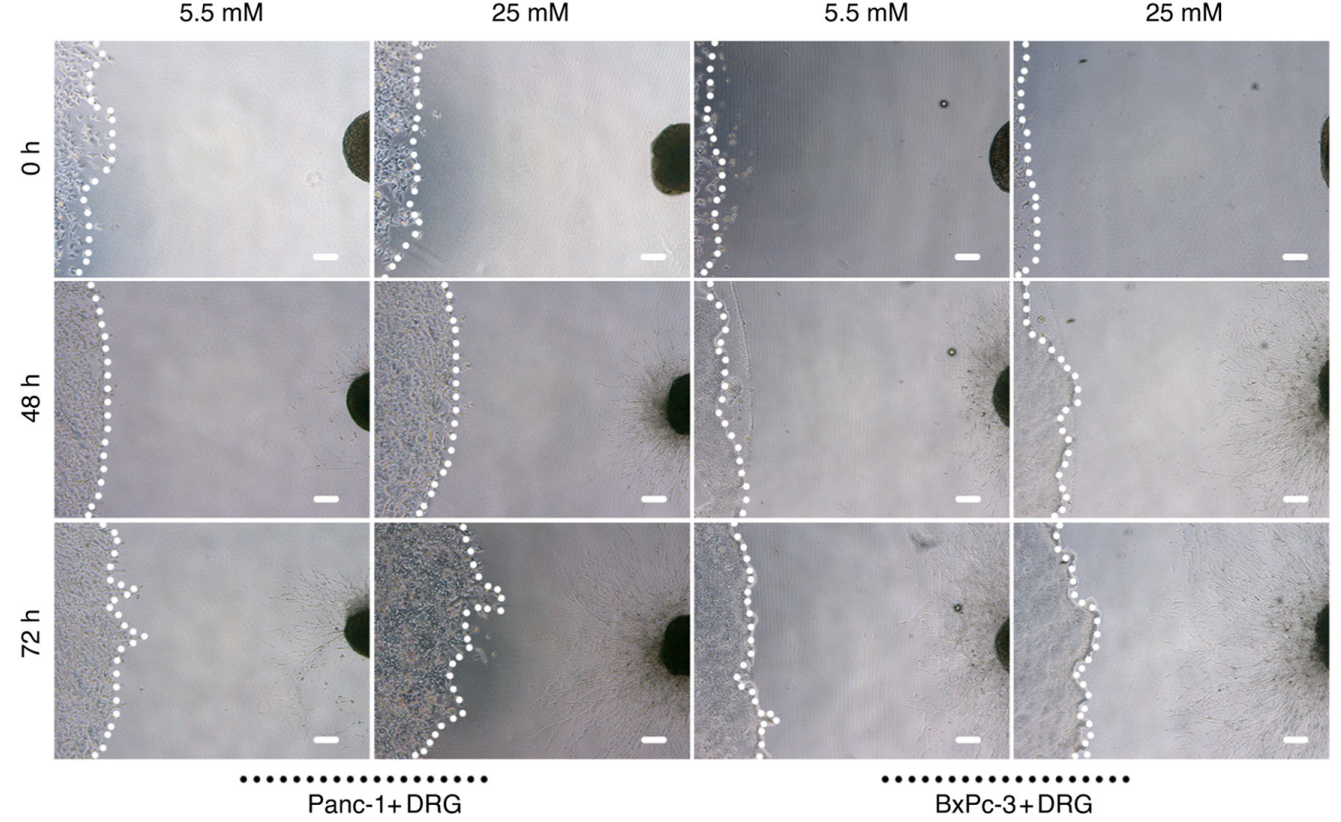

Figure 2. Hyperglycemia accelerates the NGF expression and PNI of PC. (A) Pattern diagrams of the PC cell-DRG co-culture model. (B) NGF expression in Panc-1 and BxPc-3 after 0,5.5 and $25 \mathrm{mM}$ glucose intervention. (C) The quantification of the PC cell invasion index in the euglycemia (5.5 mM glucose) and hyperglycemia (25 mM glucose) groups. (D) The quantification of the DRG outgrowth index in the euglycemia (5.5 mM glucose) and hyperglycemia ( $25 \mathrm{mM}$ glucose) groups. (E) Micrograph of the PNI in the euglycemia (5.5 mM glucose) and hyperglycemia ( $25 \mathrm{mM}$ glucose) groups when using the PC cell-DRG co-culture model. * $\mathrm{P}<0.05$ vs. $5.5 \mathrm{mM}$ glucose group. Scale bar, $200 \mu \mathrm{m}$. DRG, dorsal root ganglion; NGF, nerve growth factor; PC, pancreatic cancer; PNI, perineural invasion.

expression of NGF in PC was measured and hyperglycemia was found to result in increased NGF expression in both BxPc-3 and Panc-1 cells (Figs. 2B and S1A). By applying the PC cell-DRG co-culture model, it was also found that hyperglycemia significantly accelerated the invasion of the PC cells toward the DRG axons (Fig. 2C and E); in addition, hyperglycemia also promoted the outgrowth of the DRG axons (Fig. 2D and E). The promotion effect of hyperglycemia on the DRGs was much weaker than that on the PC cells, and this discrepancy may be due to the fact that hyperglycemia not only promotes the secretion of NGF by PC to stimulate the growth of axons, but it also has a certain toxic effect on nerve axons.

Hyperglycemia upregulates HIFl $\alpha$, which promotes the invasion and migration of PC cells. A previous study demonstrated that HIF1 $\alpha$ mediates PC cell metastasis in hyperglycemia-induced hypoxic conditions (22). Hence, the present study aimed to explore whether HIF1 $\alpha$ was participating in PC cell invasion and migration. First, PC cells were cultured with different concentrations of glucose $(0$, 5.5 and $25 \mathrm{mM}$ ) and it was found that hyperglycemia upregulated HIF1 $\alpha$ (Figs. 3A and S1B), which is consistent with the previous findings shown in Fig. 2B. Considering that HIF1 $\alpha$ is unstable under normal conditions and is stabilized under hypoxia (22), we hypothesize that hyperglycemia aggravated the hypoxic microenvironment of PC.

Next, using two online bioinformatics analysis websites, GEPIA (http://gepia.cancer-pku.cn/) and Kaplan-Meier Plotter (http://www.kmplot.com), HIF1 $\alpha$ expression was found to be high in PC and associated with a poor prognosis (Fig. 3B-D). In addition, HIFl $\alpha$ was positively correlated with the expression of neurotrophic factor NGF (Fig. 3E). To measure the 
A
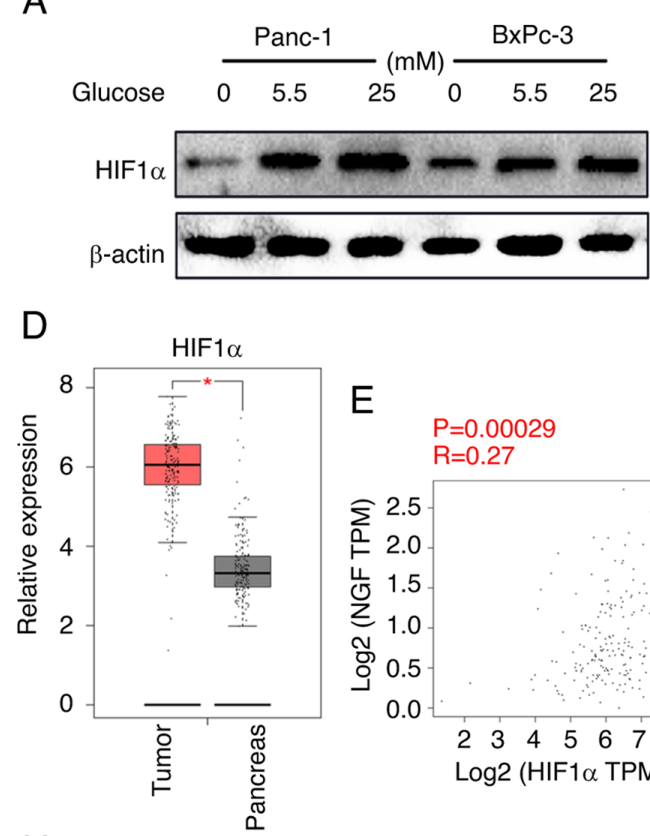

$\mathrm{H}$

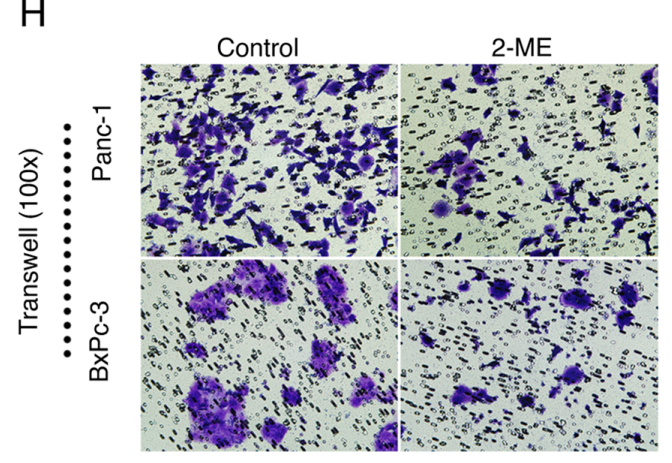

$\mathrm{J}$

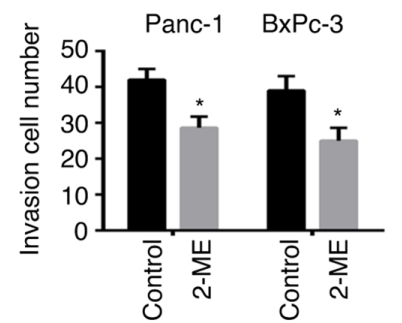

B

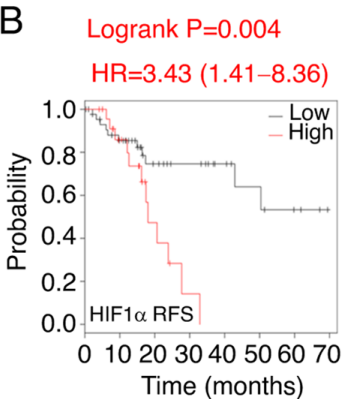

$\mathrm{F}$

$\mathrm{O}_{2}$ nor nor hypo

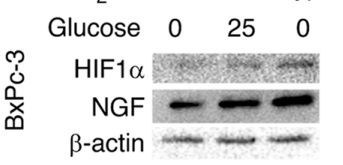

C Logrank $\mathrm{P}=0.048$

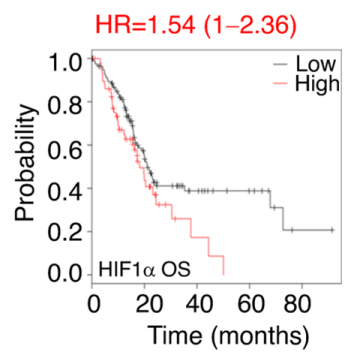

G $\mathrm{O}_{2}$ nor nor hypo

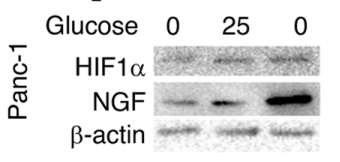

I

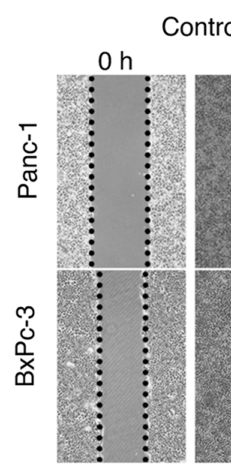

Control

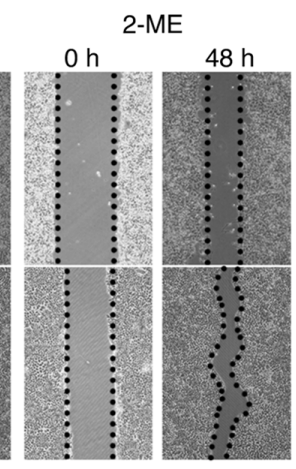

$\mathrm{K}$

Panc-1 BxPc-3

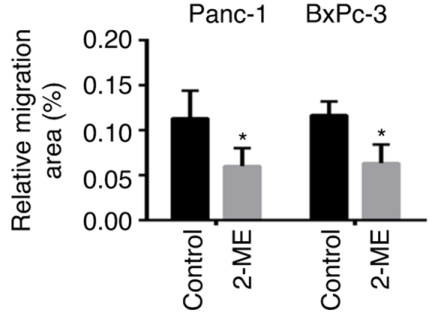

Figure 3. Hyperglycemia upregulates HIF1 $\alpha$, which promotes the invasion and migration of PC cells. (A) HIF1 $\alpha$ expression in Panc-1 and BxPc-3 after $0,5.5$ and $25 \mathrm{mM}$ glucose intervention. (B) Disease-free survival and (C) overall survival of patients with PC according to HIF1 $\alpha$ expression. (D) The relative expression of HIF1 $\alpha$ in normal and PC tissues. (E) The relative expression between HIF1 $\alpha$ and NGF. (F and G) Expression of HIF1 $\alpha$ and NGF in high-glucose and hypoxic conditions in (F) BxPc-3 and (G) Panc-1. (H and I) Cell invasion and migration ability of the control and 2-ME groups in BxPC-3 and Panc-1 cells assessed by (H) Transwell assay (crystal violet staining; x100 magnification), and (I) wound-healing assay (x50 magnification), respectively. ( $\mathrm{J}$ and $\mathrm{K})$ Quantification of $(\mathrm{H})$ and $(\mathrm{I})$, respectively. ${ }^{\mathrm{P}}<0.05$ vs. control. HIF1 $\alpha$, hypoxia inducible factor $1 \alpha$; HR, hazard ratio; PAAD, pancreatic adenocarcinoma; TPM, transcripts per million; NGF, nerve growth factor; nor, normoxia $\left(\mathrm{O}_{2}\right.$ concentration, $\left.20 \%\right)$; hypo, hypoxia $\left(\mathrm{O}_{2}\right.$, concentration $\left.1 \%\right)$; 2-ME, 2-mercaptoethanol; PC, pancreatic cancer.

influence of HIF1 $\alpha$ on PC cell invasion and migration, 2-ME $(10 \mu \mathrm{M})$ was adopted as an inhibitor of HIF1 $\alpha$ (23). The data revealed that hyperglycemia had a similar function with regard to hypoxia as to the expression of NGF and HIF1 $\alpha$, and HIF1 $\alpha$ inhibition suppressed the invasion and migration of the PC cells (Figs. 3F-K and S1C). In conclusion, it was demonstrated that hyperglycemia upregulated HIF1 $\alpha$ and that HIF1 $\alpha$ promoted the invasion and migration of the PC cells.

Hyperglycemia facilitates the invasion and migration of $P C$ cells via HIFl $\alpha$. As aforementioned, HIF1 $\alpha$ was demonstrated to promote the invasion and migration of the PC cells. Next, the PC cell-DRG co-culture model was adopted to explore whether HIF1 $\alpha$ was essential for the PNI of PC. First, si-HIF1 $\alpha$ was used to inhibit the expression of HIF1 $\alpha$, and consistent with previous findings, it was found that the expression of NGF was also decreased in both hypoxic and normoxic conditions (Figs. 4A and S1D). Next, si-HIF1 $\alpha$ - or si-NC-treated PC cells were cultured with DRGs, and after $48 \mathrm{~h}$ of co-culture, both PC cell invasion and DRG outgrowth were suppressed after HIF1 $\alpha$ downregulation (Fig. 4B-D). Combined with the aforementioned results, it can be concluded that HIF1 $\alpha$ is 
A

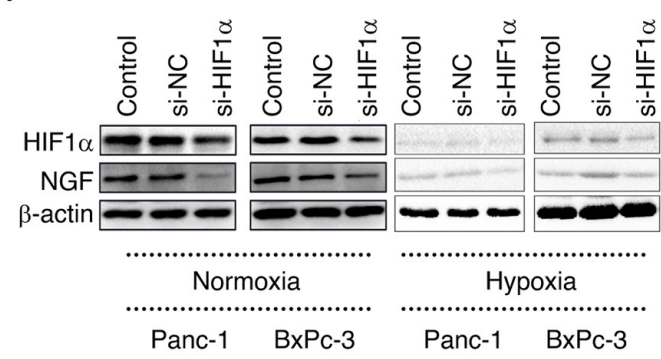

B

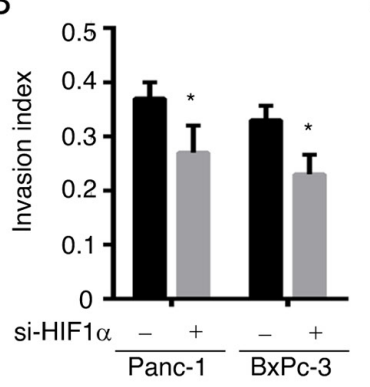

C

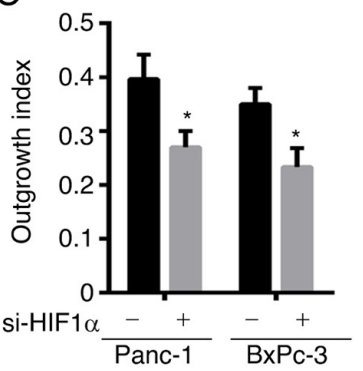

D
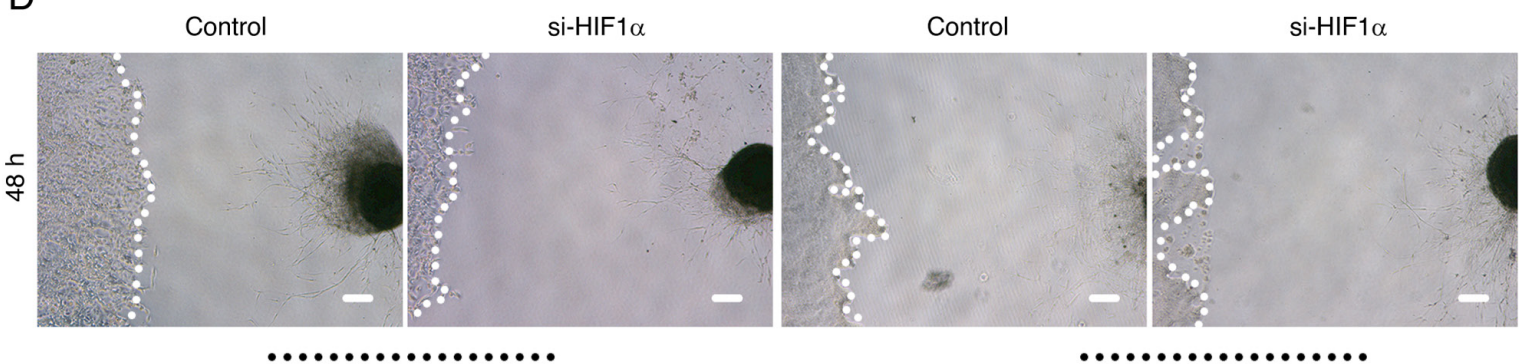

Panc-1+DRG

BXPC-3+DRG

E

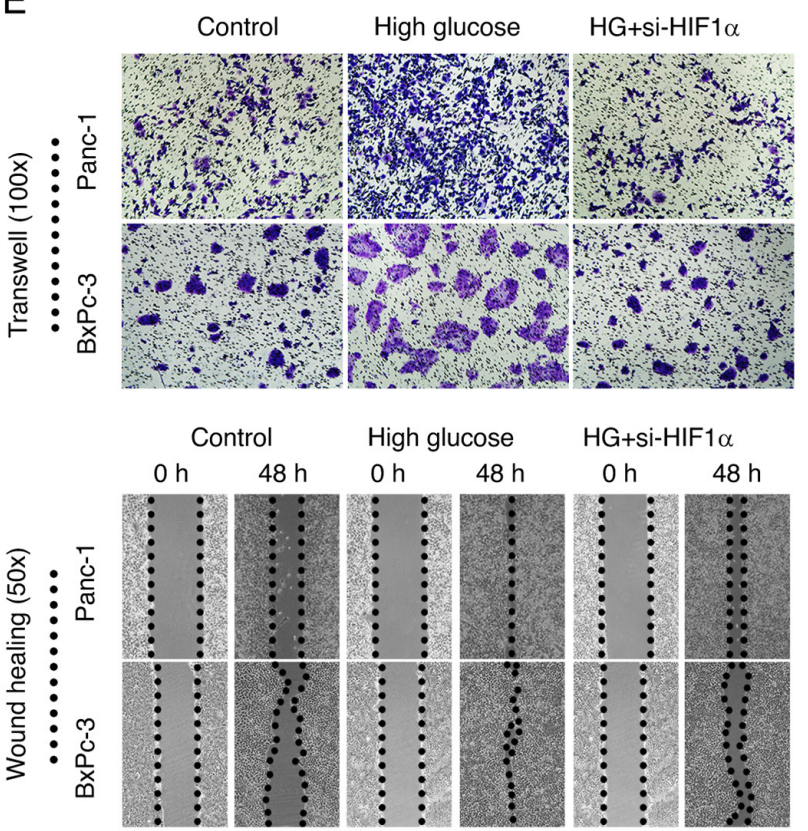

$\mathrm{F}$

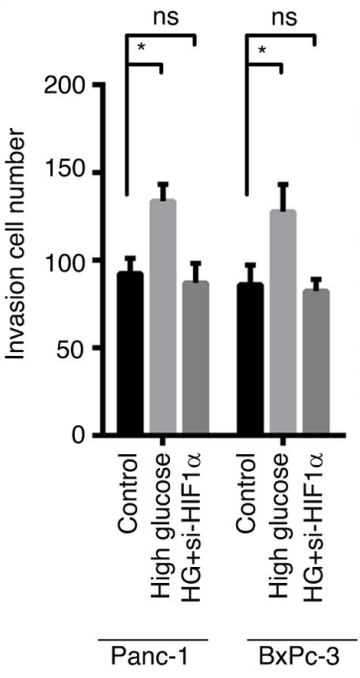

G

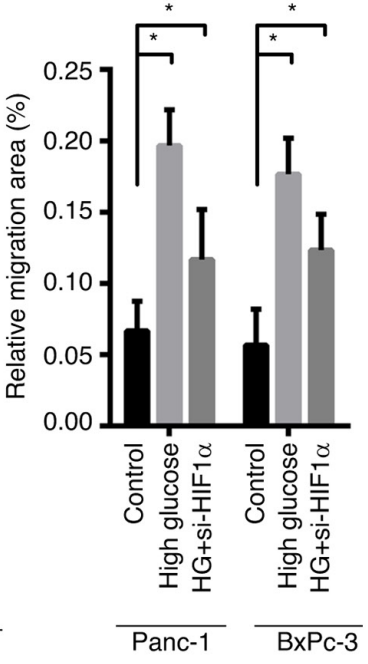

Figure 4. Hyperglycemia facilitates the invasion and migration of PC cells via HIF1 $\alpha$. (A) HIF1 $\alpha$ and NGF expression in control, si-NC and si-HIF1 $\alpha$ groups under normoxic and hypoxic conditions. (B) The quantification of the PC cell invasion index in the control and si-HIF1 $\alpha$ groups. (C) The quantification of the DRG outgrowth index in the control and si-HIF1 $\alpha$ groups. (D) The micrograph of perineural invasion in the control and si-HIF1 $\alpha$ groups using the PC cell-DRG co-culture model. (E) Cell invasive/migration ability of control, high-glucose (25 mM glucose) and high-glucose plus si-HIF1 $\alpha$ groups in BxPC-3 and Panc-1 cells assessed using a Transwell assay (crystal violet staining; x100 magnification) or wound-healing assay (x50 magnification). (F and $\mathrm{G}$ ) The quantification of (F) PC cell invasion and (G) migration ability in the control, high-glucose $(25 \mathrm{mM}$ glucose $)$ and high-glucose plus si-HIF1 $\alpha$ groups. ${ }^{*} \mathrm{P}<0.05$ vs. control group or si-NC group, as indicated. Scale bar, $200 \mu \mathrm{m}$. HIF1 $\alpha$, hypoxia inducible factor $1 \alpha$; NGF, nerve growth factor; si, small interfering; $\mathrm{NC}$, negative control; DRG, dorsal root ganglion; ns, not significant; PC, pancreatic cancer; HG, high glucose.

essential for PC cell invasion/migration and PNI. However, the present study also found that hyperglycemia promoted the invasion/migration/PNI of PC cells and that hyperglycemia can upregulate HIF1 $\alpha$. Hence, it was next demonstrated that the promoting effect of hyperglycemia on invasion/migration was HIF1 $\alpha$-dependent. Specifically, si-HIF1 $\alpha$ or si-NC was used to influence the expression of HIF1 $\alpha$ in the PC cells, which were then treated with $25 \mathrm{mM}$ glucose. As shown in Fig. 4E-G, hyperglycemia promoted the invasion/migration of the PC cells, but inhibiting HIF1 $\alpha$ abrogated this effect. In conclusion, hyperglycemia facilitated the invasion and migration of PC cells via HIF1 $\alpha$.

Hyperglycemia facilitates the PNI of PC by activating HIFla in vitro. The aforementioned results revealed that HIF1 $\alpha$ plays a vital role in the hyperglycemia-induced invasion and migration of PC cells. Therefore, the present study next aimed to analyze the role of HIF1 $\alpha$ in the PNI of PC in a background of hyperglycemia. si-HIF1 $\alpha$ or si-NC were used to influence the expression of HIF1 $\alpha$ in the PC cells, which were then cultured with DRGs 

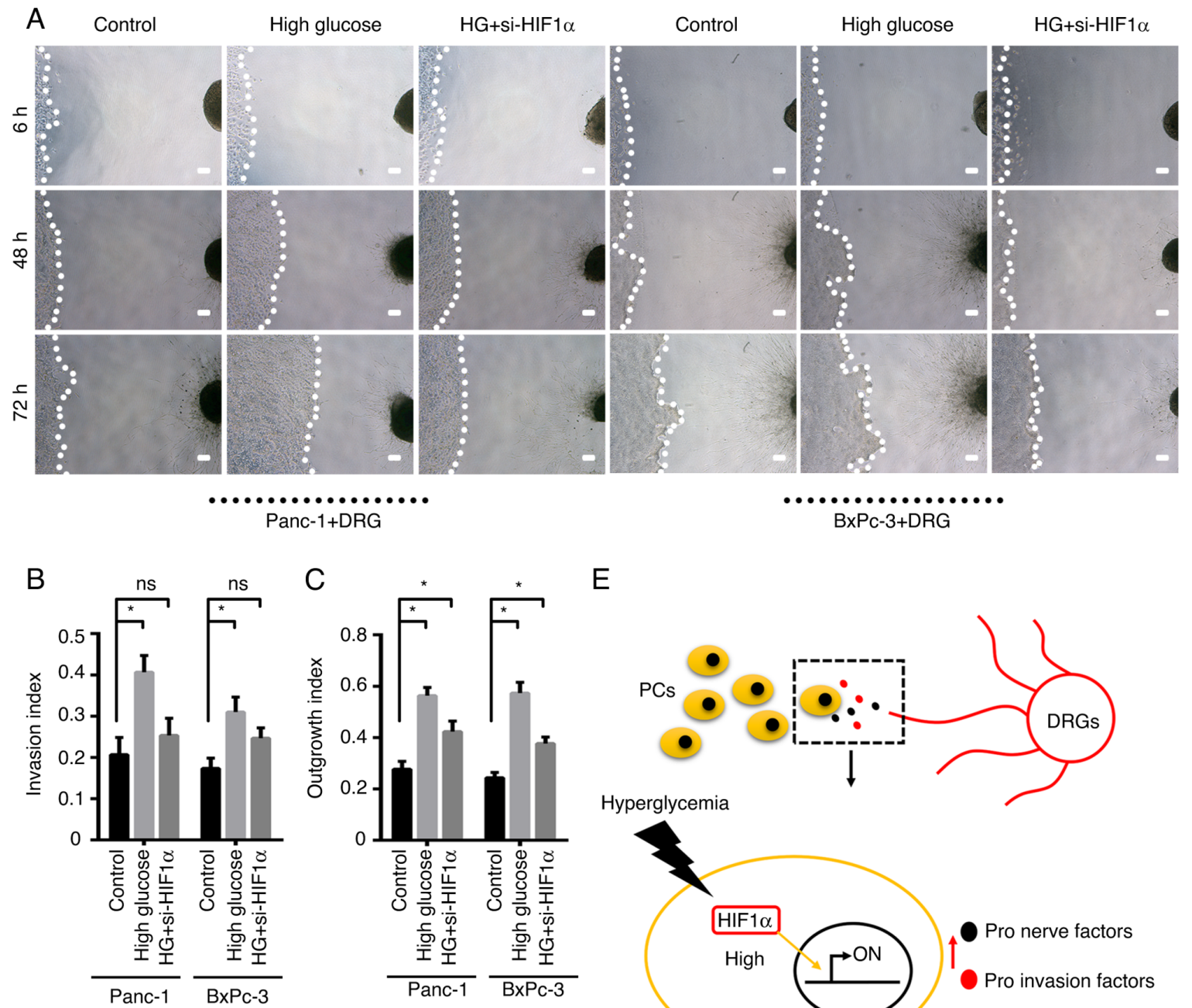

E
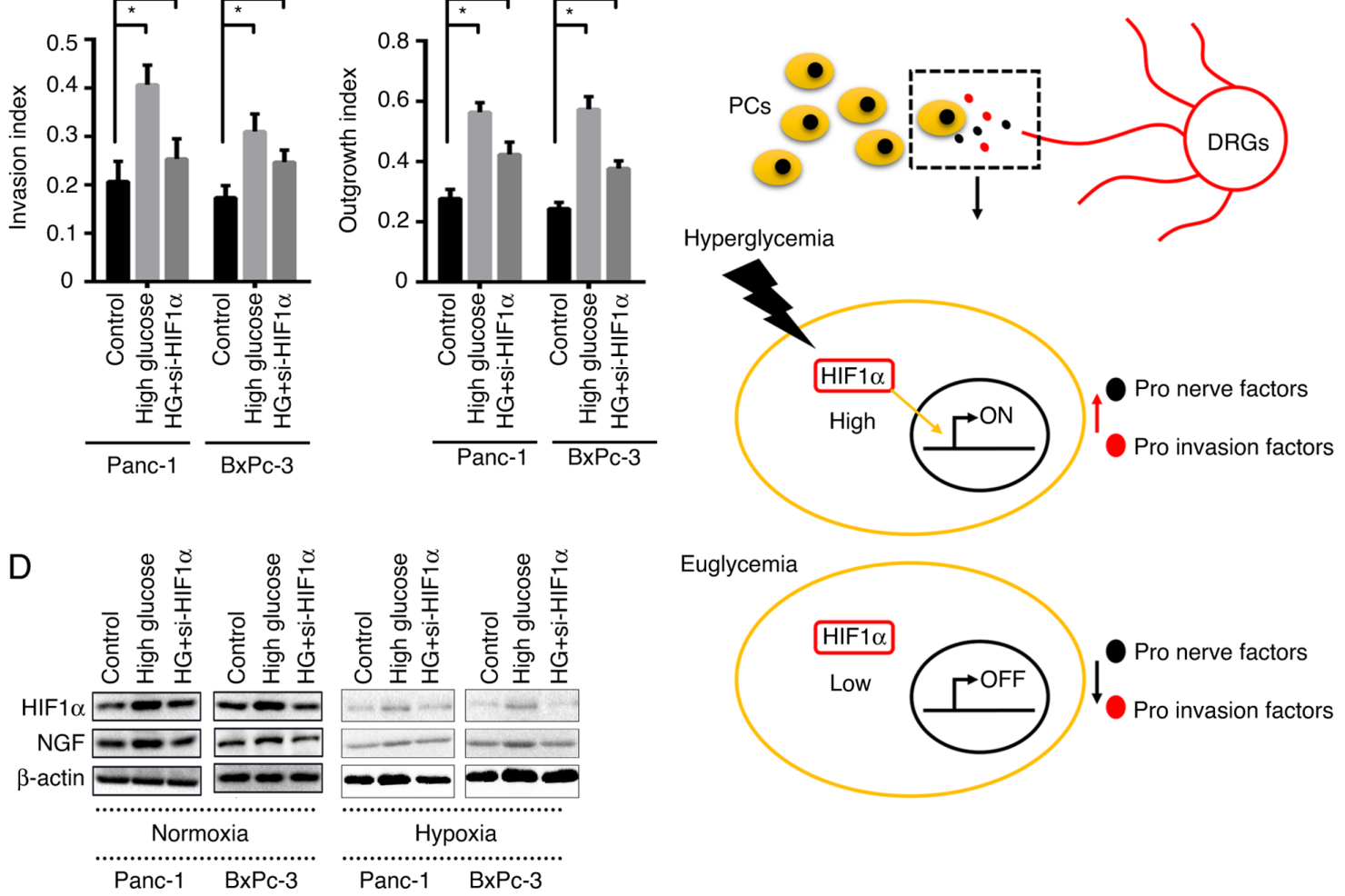

Figure 5. Hyperglycemia facilitates the PNI of PC via activation of HIFla in vitro. (A) The micrograph of PNI in the control, hyperglycemia (25 mM glucose) and hyperglycemia plus si-HIF1 $\alpha$ groups after intervention for 6, 24 and $48 \mathrm{~h}$. (B) The quantification of the PC cell invasion index in the control, high-glucose (25 mM glucose) and high-glucose plus si-HIF1 $\alpha$ groups. (C) The quantification of the DRG outgrowth index in the control, hyperglycemia (25 $\mathrm{mM}$ glucose) and hyperglycemia plus si-HIF1 $\alpha$ groups. (D) HIF1 $\alpha$ and NGF expression in the control, high-glucose (25 mM glucose) and high-glucose plus si-HIF1 $\alpha$ groups. (E) Pattern diagrams of high hyperglycemia promoting PNI of PC by activating HIF1 $\alpha$. "P<0.05. Scale bar, $200 \mu \mathrm{m}$. ns, not significant; PNI, perineural invasion; HIF1 $\alpha$, hypoxia inducible factor $1 \alpha$; NGF, nerve growth factor; si, small interfering; NC, negative control; PC, pancreatic cancer; DRG, dorsal root ganglion; HG, high glucose.

in normal or high-glucose media. After co-culture for different time points, the PC cell invasion and DRG outgrowth of these groups was measured, and hyperglycemia was found to promote the PNI of PC; however, this effect was abrogated by the inhibition of HIF1 $\alpha$ (Fig. 5A-C). In western blot assays, it was found that hyperglycemia upregulated the levels of both HIF1 $\alpha$ and NGF; however, consist with the above findings, after inhibition of HIFl $\alpha$, the expression of NGF was downregulated in both hypoxic and normoxic conditions (Figs. 5D and S1E). Hence, taken together, all of these findings indicated that hyperglycemia promoted the PNI of PC in a HIFl $\alpha$-dependent manner (Fig. 5E).

Hyperglycemia promotes the PNI of PC in a HIFla-dependent manner in vivo. The present study demonstrated that hyperglycemia promoted the PNI of PC in a HIFl $\alpha$-dependent manner in vitro; however, whether this phenomenon occurred in actual organisms was still unclear. Hence, by using STZ injections and sciatic nerve grafts, an in vivo PNI sciatic nerve infiltrating 
A
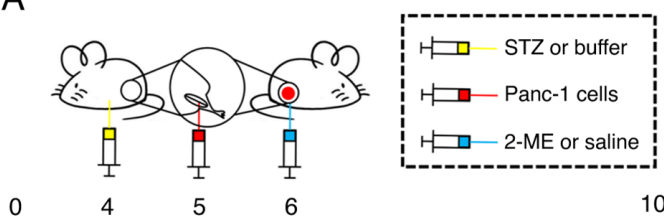

10 (weeks)

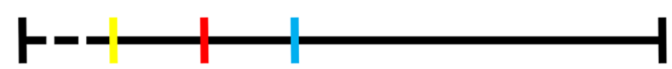

Intraperitoneal injection, $4^{\text {week }}$
Intravenous injection of the sciatic nerve, $5^{\text {week }}$ Intraperitoneal injection, $6^{\text {week }}$

C

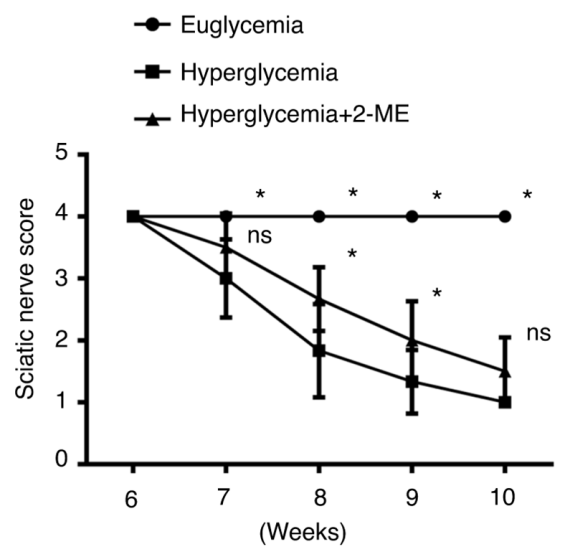

E

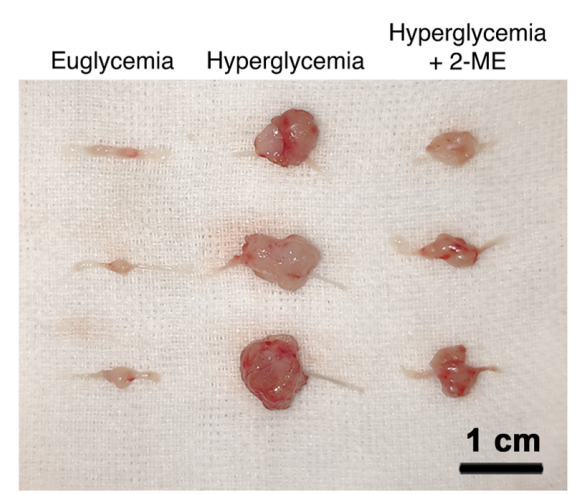

B

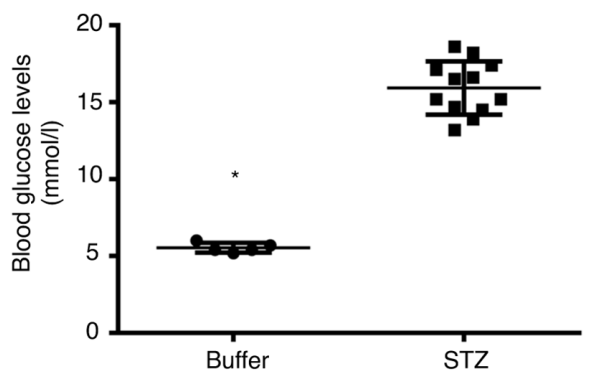

D

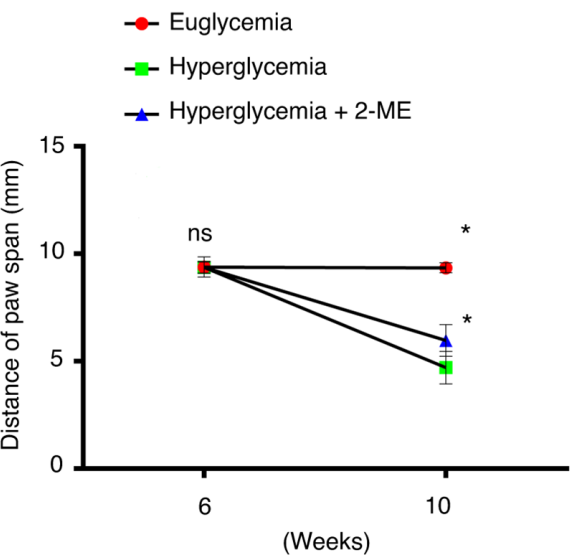

F

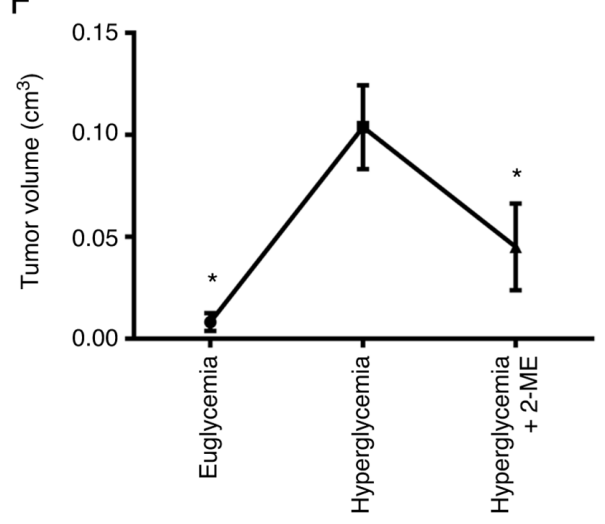

Figure 6. Hyperglycemia promotes the PNI of pancreatic cancer cells in a HIF1 $\alpha$-dependent manner in vivo. (A) The pattern diagram of the establishment of the in vivo PNI sciatic nerve infiltrating tumor model with a background of hyperglycemia. (B) Blood glucose levels of mice in the euglycemia and hyperglycemia groups. (C and D) The quantification of (C) the sciatic nerve score and (D) the distance of paw span in the euglycemia, hyperglycemia and hyperglycemia plus 2-ME groups. (E and F) The macrophotography of (E) tumor size and (F) the quantification of tumor volume in the euglycemia, hyperglycemia and hyperglycemia plus 2-ME groups. The hyperglycemia group was used to compare with the other two groups. * $<<0.05$ vs. hyperglycemia or STZ group. Scale bar, $1 \mathrm{~cm}$. ns, not significant; STZ, streptozotocin; 2-ME, 2-mercaptoethanol; PNI, perineural invasion.

tumor model (Fig. 6A) was established to explore the influence of hyperglycemia on the PNI of PC.

First, the blood glucose levels of the mice were detected on the 7 th day after injecting $150 \mathrm{mg} / \mathrm{kg} \mathrm{STZ}$ or sodium citrate buffer, and STZ treatment was found to effectively induce hyperglycemia in the mice (Fig. 6B). Next, the sciatic nerve function in the three groups of mice was monitored and evaluated using a sciatic nerve score and the distance of the paw span, and it was found that hyperglycemia significantly affected the function of the sciatic nerve; however, HIF1 $\alpha$ inhibition improved this phenomenon (Fig. 6C and D).

After the sciatic nerve and the surrounding tumor tissue were dissected out, hyperglycemia was found to promote the infiltration of the PC cells and tumor growth, while HIF1 $\alpha$ inhibition partially abrogated this effect (Fig. 6E and F). In conclusion, the present study demonstrated that hyperglycemia promoted the PNI of PC in a HIF1 $\alpha$-dependent manner in vivo.

\section{Discussion}

$\mathrm{PC}$ is one of the most highly malignant cancers, with a 5-year survival rate of $<9 \%$ (1). Difficulties in its early diagnosis and rapid progression, and a lack of therapeutic strategies are the main clinical features of PDAC, which together lead to its poor prognosis (24). In total, $<20 \%$ of patients with PC have the opportunity to undergo radical excision, leaving only certain adjuvant chemotherapies, such as gemcitabine, S-1 and FOLFIRINOX, for treatment; however, even among patients who undergo surgery, $80 \%$ still rapidly progress to the late-stage of disease (25). Hence, early prevention and 
diagnosis, rather than finding ways to treat PC, is a crucial strategy to improve its poor prognosis.

As the main pathological feature of PDAC (8), PNI is closely associated with its progression and poor prognosis (26-28). The cross-talk between tumor cells and nerves promotes PNI. Specifically, on the one hand, PC cells secrete neurotrophic factors, such as NGF, that promote the growth of nerves toward them, while on the other hand, the activation of the migration and invasion-related pathways of the PC cells themselves triggers them to migrate toward and invade nerves (19). Once PC cells invade into the nerves, they trigger an inflammatory response that further destroys the structure of the nerves, and neurotrophic factors (such as NGF-activating transient receptor potential cation channel subfamily $\mathrm{V}$ member 1) secreted by PC increase the sensitivity of the nerves to stimulation, causing cancer-related pain; this entire process induces high rates of cancer metastasis and cancer recurrence $(28,29)$.

It is important to keep in mind that cancer cells and nerves do not have an isolated existence in tumor tissues; they are surrounded by pancreatic stellate cells (PSCs), immune cells, endothelial cells and other elements, such as the extracellular matrix. These elements form a complex tumor microenvironment (TME) that promotes the PC to invade the nerves (4,30-32). Indeed, as aforementioned, after they invade the nerves, the inflammation caused by the PC cells induces immune cell infiltration, PSC activation and a series of mesenchymal remodeling reactions to build an even more tumor-promoting TME $(7,33,34)$. Such a cascade-amplifying loop exacerbates the progression of PC and PNI. Notably, in transgenic mouse models of $\mathrm{PC}$, researchers have demonstrated that PNI is an early precancerous lesion of PC and that anti-PNI treatment is beneficial for the prognosis $(5,26,35,36)$.

As a clear risk factor of PC, hyperglycemia promotes the progression of $\mathrm{PC}$ by modulating proliferation/invasion/migration, inducing apoptotic/autophagy and increasing the chemoresistance of PC $(14,20,22)$. However, although the PNI-promoting effect of hyperglycemia has been previously reported $(16,37)$, the underlying mechanism remains unclear. The present study demonstrated that hyperglycemia promoted the invasion/migration of PC cells, and the expression of NGF was elevated. All of these phenomena were HIF1 $\alpha$-dependent. HIF1- $\alpha$ can be activated by a tolerable level of reactive oxygen species (ROS) (38), and ROS can develop into oxidative stress, which is beneficial for the maintenance of a tumorigenic condition (39). Therefore, more research about HIF1- $\alpha$, ROS and oxidative stress is necessary. Indeed, in the present study, short-term hyperglycemia caused little damage to the DRGs axons and promoted both PC cell PNI and DRG outgrowth in a HIF $1 \alpha$-dependent manner. However, with prolongation of the exposure to high glucose, the outgrowth of the DRGs was suppressed, and this may be caused by the hyperglycemia damaging the structure of the axons, such as the Schwann cells, a necessary cellular element for the growth of axons (16). Long-term hyperglycemia increases the secretion of pro-inflammatory factors, such as interleukin-6, tumor necrosis factor- $\alpha$ and cyclooxygenase- 2 , and these factors may be closely related to the development of tumors; however, they will destroy the nerve structure and inhibit the growth of axons (14). Nevertheless, we consider that the nerve damage caused by hyperglycemia is not inconsistent with the occurrence of PNI. Instead, PC cells are more likely to penetrate damaged nerves in a localized inflammatory environment. Consistent with this, the present study also found that long-term hyperglycemia does promote the infiltration and growth of PC in vivo. This may be related to its activating effect on HIF1 $\alpha$. In the study by $\mathrm{Li}$ and $\mathrm{Ma}$ (39), it was suggested that the hyperglycemic conditions increased the expression of cytokines by PC, and caused demyelinization and axonal degeneration of nerves. This is consistent with the present results showing that NGF generated by PC can promote the PNI of PC. More detailed research needs to be conducted to clarify the specific mechanisms involved in this phenomenon.

In conclusion, all of the findings of the present study revealed that a high-glucose microenvironment enhances the invasion/migration ability of PC. In addition, hyperglycemia upregulated the expression of NGF and promoted the PNI of PC by activating HIF1 $\alpha$. However, the underlying mechanism requires additional investigation.

\section{Acknowledgements}

Not applicable.

\section{Funding}

This study was financially supported by Shaanxi Province International Science and Technology Cooperation Key Project Plan (2014kw23-07, 2019KW-035), the Second Affiliated Hospital of Xi'an Jiaotong University Fund Youth Project (YJ(QN)201304), the National Natural Science Foundation of China (NSFC 81872008 to WZ), the Science and Technology Innovation as a Whole Plan Projects of Shaanxi Province (no. 2016KJZDSF01-05-01), and the Fundamental Research Funds for the Central University (grant serial no. xjj2018117).

\section{Availability of data and materials}

The datasets used during the current study are available from the corresponding author upon reasonable request.

\section{Authors' contributions}

$\mathrm{WM}$ and $\mathrm{WZ}$ performed the experiments, and $\mathrm{XZ}$ and $\mathrm{YM}$ helped analyze the data. YZ and BW helped to design the project. WL, SM, WM and LZ analyzed the data and wrote the manuscript. All authors have read and approved the manuscript. WM, WZ, XZ, YM, YZ, BW, WL, SM and LZ have seen and confirmed the authenticity of the raw data generated during the study.

\section{Ethics approval and consent to participate}

All animal experiments were conducted in strict accordance with the Declaration of Helsinki, and all protocols were approved by the Ethical Committee of the First Affiliated Hospital of Xi'an Jiaotong University (Xi'an, China).

\section{Patient consent for publication}

Not applicable. 


\section{Competing interests}

The authors declare that they have no competing interests.

\section{References}

1. Siegel RL, Miller KD and Jemal A: Cancer statistics, 2019. CA Cancer J Clin 69: 7-34, 2019.

2. Torgeson A, Garrido-Laguna I, Tao R, Cannon GM, Scaife CL and Lloyd S: Value of surgical resection and timing of therapy in patients with pancreatic cancer at high risk for positive margins. ESMO Open 3: e000282, 2018.

3. Kamisawa T, Wood LD, Itoi T and Takaori K: Pancreatic cancer. Lancet 388: 73-85, 2016.

4. Liebig C, Ayala G, Wilks JA, Berger DH and Albo D: Perineural invasion in cancer: A review of the literature. Cancer 115 3379-3391, 2009.

5. Demir IE, Ceyhan GO, Liebl F, D'Haese JG, Maak M and Friess H: Neural invasion in pancreatic cancer: The past, present and future. Cancers (Basel) 2: 1513-1527, 2010

6. Liang D, Shi S, Xu J, Zhang B, Qin Y, Ji S, Xu W, Liu J, Liu L, Liu C, et al: New insights into perineural invasion of pancreatic cancer: More than pain. Biochim Biophys Acta 1865: 111-122, 2016.

7. Jurcak $N$ and Zheng L: Signaling in the microenvironment of pancreatic cancer: Transmitting along the nerve. Pharmacol Ther 200: 126-134, 2019.

8. Saloman JL, Albers KM, Rhim AD and Davis BM: Can stopping nerves, stop cancer. Trends Neurosci 39: 880-889, 2016

9. Nan L, Qin T, Xiao Y, Qian W, Li J, Wang Z, Ma J, Ma Q and Wu Z: Pancreatic stellate cells facilitate perineural invasion of pancreatic cancer via $\mathrm{HGF} / \mathrm{c}-$ Met pathway. Cell Transplant 28: $1289-1298,2019$.

10. Nagakawa T, Kayahara M, Ueno K, Ohta T, Konishi I and Miyazaki I: Clinicopathological study on neural invasion to the extrapancreatic nerve plexus in pancreatic cancer. Hepatogastroenterology 39: 51-55, 1992.

11. Scappaticcio L, Maiorino MI, Bellastella G, Giugliano D and Esposito K: Insights into the relationships between diabetes, prediabetes, and cancer. Endocrine 56: 231-239, 2017.

12. Huang Y, Cai X, Qiu M, Chen P, Tang H, Hu Y and Huang Y: Prediabetes and the risk of cancer: A meta-analysis. Diabetologia 57: 2261-2269, 2014

13. Prizment AE, Gross M, Rasmussen-Torvik L, Peacock JM and Anderson KE: Genes related to diabetes may be associated with pancreatic cancer in a population-based case-control study in Minnesota. Pancreas 41: 50-53, 2012.

14. Li W, Zhang X, Sang H, Zhou Y, Shang C, Wang Y and Zhu H: Effects of hyperglycemia on the progression of tumor diseases. J Exp Clin Cancer Res 38: 327, 2019.

15. Li J, Ma Q, Liu H, Guo K, Li F, Li W, Han L, Wang F and Wu E: Relationship between neural alteration and perineural invasion in pancreatic cancer patients with hyperglycemia. PLoS One 6 : e17385, 2011.

16. Li J, Ma J, Han L, Xu Q, Lei J, Duan W, Li W, Wang F, Wu E, $\mathrm{Ma} \mathrm{Q}$ and Huo X: Hyperglycemic tumor microenvironment induces perineural invasion in pancreatic cancer. Cancer Biol Ther 16: 912-921, 2015.

17. Larrieta ME, Vital P, Mendoza-Rodríguez A, Cerbón M and Hiriart M: Nerve growth factor increases in pancreatic beta cells after streptozotocin-induced damage in rats. Exp Biol Med (Maywood) 231: 396-402, 2006

18. Dang C, Zhang Y, Ma Q and Shimahara Y: Expression of nerve growth factor receptors is correlated with progression and prognosis of human pancreatic cancer. J Gastroenterol Hepatol 21: 850-858, 2006

19. Li X, Wang Z, Ma Q, Xu Q, Liu H, Duan W, Lei J, Ma J, Wang X, Lv S, et al: Sonic hedgehog paracrine signaling activates stromal cells to promote perineural invasion in pancreatic cancer. Clin Cancer Res 20: 4326-4338, 2014

20. Zhou C, Qian W, Li J, Ma J, Chen X, Jiang Z, Cheng L, Duan W, Wang Z, Wu Z, et al: High glucose microenvironment accelerates tumor growth via SREBP1-autophagy axis in pancreatic cancer. J Exp Clin Cancer Res 38: 302, 2019.
21. Li W, Liu H, Qian W, Cheng L, Yan B, Han L, Xu Q, Ma Q and Ma J: Hyperglycemia aggravates microenvironment hypoxia and promotes the metastatic ability of pancreatic cancer. Comput Struct Biotechnol J 16: 479-487, 2018.

22. Ilic M and Ilic I: Epidemiology of pancreatic cancer. World J Gastroenterol 22: 9694-9705, 2016.

23. Xu WN, Zheng HL, Yang RZ, Jiang LS and Jiang SD: HIF-1a regulates glucocorticoid-induced osteoporosis through PDK1/ AKT/mTOR signaling pathway. Front Endocrinol (Lausanne) 28: $922,2020$.

24. Wolfgang CL, Herman JM, Laheru DA, Klein AP, Erdek MA, Fishman EK and Hruban RH: Recent progress in pancreatic cancer. CA Cancer J Clin 63: 318-348, 2013.

25. Yang YH, Liu JB, Gui Y, Lei LL and Zhang SJ: Relationship between autophagy and perineural invasion, clinicopathological features, and prognosis in pancreatic cancer. World J Gastroenterol 23: 7232-7241, 2017.

26. Deborde S, Omelchenko T, Lyubchik A, Zhou Y, He S, McNamara WF, Chernichenko N, Lee SY, Barajas F, Chen $\mathrm{CH}$, et al: Schwann cells induce cancer cell dispersion and invasion. J Clin Invest 126: 1538-1554, 2016.

27. Demir IE, Friess H and Ceyhan GO: Neural plasticity in pancreatitis and pancreatic cancer. Nat Rev Gastroenterol Hepatol 12: 649-659, 2015

28. Zhu Y, Colak T, Shenoy M, Liu L, Pai R, Li C, Mehta K and Pasricha PJ: Nerve growth factor modulates TRPV1 expression and function and mediates pain in chronic pancreatitis. Gastroenterology 141: 370-377, 2011

29. Bressy C, Lac S, Nigri J, Leca J, Roques J, Lavaut MN, Secq V, Guillaumond F, Bui TT, Pietrasz D, et al: LIF drives neural remodeling in pancreatic cancer and offers a new candidate biomarker. Cancer Res 78: 909-921, 2018.

30. Amit M, Na'ara S, Leider-Trejo L, Binenbaum Y, Kulish N, Fridman E, Shabtai-Orbach A, Wong RJ and Gil Z: Upregulation of RET induces perineurial invasion of pancreatic adenocarcinoma. Oncogene 36: 3232-3239, 2017.

31. Pinho AV, Van Bulck M, Chantrill L, Arshi M, Sklyarova T, Herrmann D, Vennin C, Gallego-Ortega D, Mawson A, GiryLaterriere $\mathrm{M}$, et al: $\mathrm{ROBO} 2$ is a stroma suppressor gene in the pancreas and acts via TGF- $\beta$ signalling. Nat Commun 9: 5083, 2018.

32. Cavel O, Shomron O, Shabtay A, Vital J, Trejo-Leider L, Weizman N, Krelin Y, Fong Y, Wong RJ, Amit M and Gil Z: Endoneurial macrophages induce perineural invasion of pancreatic cancer cells by secretion of GDNF and activation of RET tyrosine kinase receptor. Cancer Res 72: 5733-5743, 2012.

33. De Oliveira T, Abiatari I, Raulefs S, Sauliunaite D, Erkan M, Kong B, Friess H, Michalski CW and Kleeff J: Syndecan-2 promotes perineural invasion and cooperates with K-ras to induce an invasive pancreatic cancer cell phenotype. Mol Cancer 11: 19, 2012.

34. Saloman JL, Albers KM, Li D, Hartman DJ, Crawford HC, Muha EA, Rhim AD and Davis BM: Ablation of sensory neurons in a genetic model of pancreatic ductal adenocarcinoma slows initiation and progression of cancer. Proc Natl Acad Sci USA 113: 3078-383, 2016 .

35. Demir IE, Boldis A, Pfitzinger PL, Teller S, Brunner E, Klose N, Kehl T, Maak M, Lesina M, Laschinger M, et al: Investigation of Schwann cells at neoplastic cell sites before the onset of cancer invasion. J Natl Cancer Inst 106: dju184, 2014.

36. Meier JJ and Giese A: Diabetes associated with pancreatic diseases. Curr Opin Gastroenterol 31: 400-406, 2015.

37. Pavlova NN and Thompson CB: The emerging hallmarks of cancer metabolism. Cell Metab 23: 27-47, 2016.

38. Chen X, Wanggou S, Bodalia A, Zhu M, Dong W, Fan JJ, Yin WC, Min HK, Hu M, Draghici D, et al: A Feedforward mechanism mediated by mechanosensitive ion channel PIEZO1 and tissue mechanics promotes glioma aggression. Neuron 100: 799-815.e7, 2018

39. Li J and Ma Q: Hyperglycemia promotes the perineural invasion in pancreatic cancer. Med Hypotheses 71: 386-389, 2008.

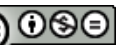

This work is licensed under a Creative Commons Attribution-NonCommercial-NoDerivatives 4.0 International (CC BY-NC-ND 4.0) License. 